\title{
LV. The electrical conductivity of flames
}

\section{Harold A. Wilson M.A. D.Sc.}

To cite this article: Harold A. Wilson M.A. D.Sc. (1905) LV. The electrical conductivity of flames, Philosophical Magazine Series 6, 10:58, 476-485, DOI: 10.1080/14786440509463395

To link to this article: http://dx.doi.org/10.1080/14786440509463395

曲 Published online: 16 Apr 2009.

Submit your article to this journal $\pi$

Џll Article views: 3

Q View related articles $\asymp$

4 Citing articles: 6 View citing articles 주다. 
The same property may belong to impure platinum, and the corresponding critical temperature may he even lower than that of pure platinum.

When the platinum is heated to the critical temperature in question the gases begin to combine, and if the platinum is heated still further, the rate of combination thereby set up in the gases increases with the temperature of the metal.

After heating the platinum sufficiently to start the reaction of the gases, the reaction may be temporarily renewed by raising the platinum to a temperature distinctly lower than that which was required to start the reaction.

The reaction between the gases is not produced by heating them to a temperature at which they combine of themselves, but is probably connected with the corpuscular discharge which is known to be emitted by platinum.

The experiments mentioned in this paper were carried out in the laboratory of Professor Townsend, the Wykeham Professor of Physics, to whom I wish to express my thanks.

LV. The Electrical Conductivity of Flames. By HAROLD A. WILson, M.A., D.Se., Fellow of Trinity College, Cambridge, and Lecturer on Physics in King's College, London *.

(1) Flames containing no Salt Vapour.

THE following paper contains an account of a series of experiments on the conductivity of a coal-gas flame for electricity between platinum electrodes immersed in the flame $t$. In order to study the variation of the current with the distance between the electrodes and the fall of potential along the flame, a special burner was used to produce a long narrow flame. The burner consisted of a fused quartz tube $25 \mathrm{cms}$. long and $2 \mathrm{cms}$. in diameter, having a single row of holes each $1.5 \mathrm{~mm}$. in diameter parallel to its axis. There were 40 holes uniformly distributed into a row $20 \mathrm{cms}$. long. One end of the tube was closed with an indiarubber stopper, and the other was connected by means of an indiarubber tube to a large Bunsen burner. The mixture of coal-gas and air supplied by the Bunsen burner was burnt at the row of holes, and formed a fairly uniform tlame $20 \mathrm{cms}$. long and about $4 \mathrm{cms}$. high. As electrodes two parallel disks of platinum were used, each $1 \mathrm{~cm}$. in diameter. One of these

* Communicated by the Physical Society : read June 16, 1905.

$t$ An excellent account of the present state of our knowledge of this subject by F. L. Tufts is contained in J. Stark's Jahrbuch der Radioaktivitat und Elektronik, 1 Band, 1 Heft (1904). 
was supported near one end of the flame and the other was fixed to a stand sliding in grooves parallel to the flame, so that it could be moved along horizontally in the flame and so placed at any desired distance from the fixed electrode. Since the quartz tube was a good insulator, a current could be passed horizontally from one end of the flame to the other without fear of any of it going through the tube instead of the flame. This arrangement of apparatus is shown diagrammatically in fig. 1 .

Fig. 1.

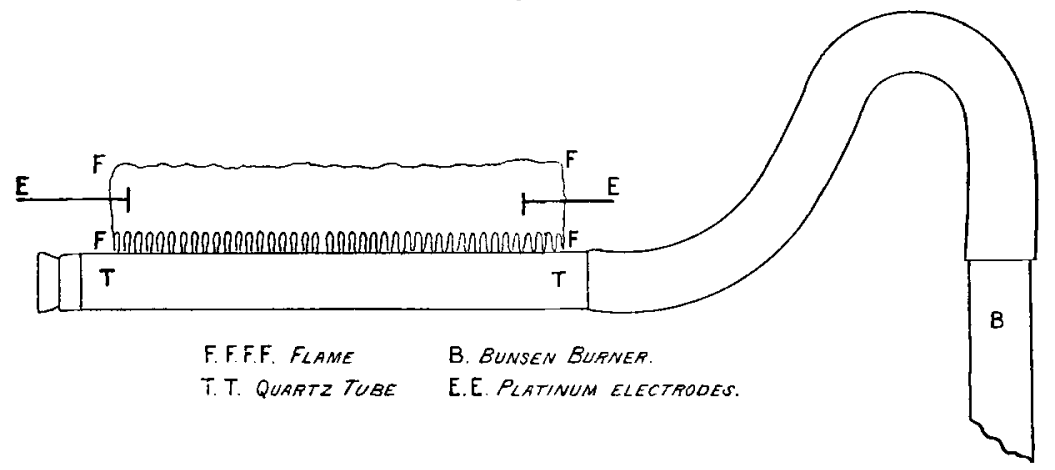

The current through the flame between the electrodes was measured by means of a moving-coil galvanometer, and the potential-difference between the electrodes by means of an electrostatic voltmeter. The electrodes were bright red hot. The variation of the current with the distance between the electrodes for different potential-differences will be first considered. The following table gives the observed galvanometer deflexions. Each number is the mean of several observations $\left(1=8 \cdot 8 \times 10^{-9}\right.$ ampere $)$.

\begin{tabular}{|c|c|c|c|c|c|}
\hline \multirow{2}{*}{$\begin{array}{l}\text { Potential } \\
\text { Difference. }\end{array}$} & \multicolumn{5}{|c|}{ Distance between Electrodes. } \\
\hline & $1 \mathrm{~cm}$ & $45 \mathrm{cms}$. & $9 \mathrm{cms}$ & 13.5 cms. & $18 \mathrm{cms}$. \\
\hline 600 volts. ......... & 310 & 304 & 295 & 280 & 270 \\
\hline $400, \quad, \ldots \ldots \ldots$ & 255 & $24 \overline{7}$ & 240 & 230 & 215 \\
\hline $200,, \ldots \ldots \ldots$ & 175 & 170 & 165 & 155 & 143 \\
\hline ........... & 130 & 125 & 115 & 104 & 90 \\
\hline 40 & 67 & 64 & 57 & 53 & 48 \\
\hline $20 \%$ & 42 & 39 & 35 & 32 & 29 \\
\hline $10, ", \ldots \ldots \ldots$ & 22 & 20 & 16 & 14 & 13 \\
\hline $4, " \ldots \ldots \ldots$ & 9 & 8 & 7 & 6 & $5 \cdot 3$ \\
\hline 2, & 5 & $4 \cdot 7$ & 4 & $3 \cdot 5$ & 3 \\
\hline
\end{tabular}


It will be seen that in every case the current falls off slowly with increasing distance between the electrodes.

The fall of potential between the electrodes was examined by means of a third electrode, consisting of a fine horizontal wire which was put in between the disk electrodes and could be moved along from one to the other. Its potential was measured by means of a Kelvin's multicellular electrostatic voltmeter.

Fig. 2 shows the variation of the potential along the flame obtained as just described. The distance between the disks was 17.7 cms. and the P.D. used 550 volts. It will be seen that there is a sudden fall of potential near each electrode and a uniform gradient in the space between the electrodes.

Fig. 2.

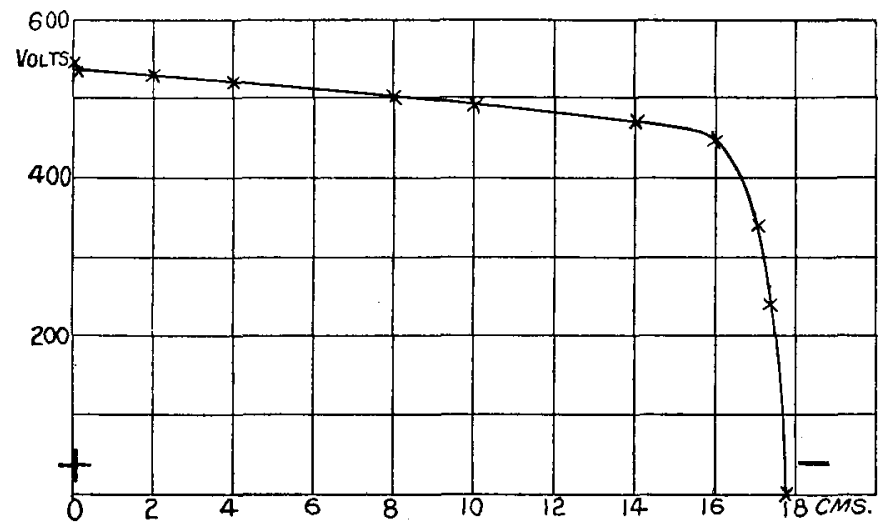

Let $n_{1}=$ number of positive ions present per c.c.

$$
\begin{aligned}
& n_{2}=\text { negative ", " " } \\
& k_{1}=\text { veiocity of positive ions due to one volt per } \mathrm{cm} . \\
& k_{2}=\text { negative ", " " " } \\
& \mathrm{X}=\text { electric intensity in volts per cm. } \\
& e=\text { charge on one ion. } \\
& i=\text { current density. }
\end{aligned}
$$

Then we have the well-known equation

$$
i=\mathrm{X} e\left(k_{1} n_{1}+k_{2} n_{2}\right) \cdot
$$

Where $\mathrm{X}$ is uniform $n_{1}=n_{2}$, so that $i=\mathrm{X} e n\left(k_{1}+k_{2}\right)$.

According to this equation we should expect the current through the flame to be proportional to the potential gradient existing between the electrodes. To test this, two small electrodes were put in the flame $0.5 \mathrm{~cm}$. apart, and the Y.D. between them was measured by means of a quadrant electrometer. It was found that the P.D. between them was rery 
nearly proportional to the current through the flame. The following are some of the results obtained:-

\begin{tabular}{|c|c|c|}
\hline $\begin{array}{c}\text { Current. } \\
(\mathbf{C}) .\end{array}$ & P.D. & P.D. $\div$ C. \\
\hline 270 & 4.0 volts. & 0.0148 \\
54 & 0.8, & 0.0148 \\
18 & 0.25, & 0.0139 \\
\hline
\end{tabular}

The P.D. between the two small electrodes varied to some extent as they were moved along the flame together, owing to the non-uniformity of the flame, but at any one point not very near either electrode it was always proportional to the current. Near the negative electrode the P.D. became too large to be measured on the quadrant electrometer, and very close to the positive electrode it also became large.

The fall of potential $(V)$ between the disk electrodes may be regarded as made up of three parts - the sudden fall near the negative electrode, say $\mathrm{V}_{2}$; the fall near the positive electrode, say $V_{1}$; and the fall in the uniform gradient, which is proportional to the current and to the distance between the electrodes. Hence approximately

$$
\mathrm{V}=\mathrm{V}_{1}+\mathrm{V}_{2}+\mathrm{AC} d
$$

where $\mathrm{A}$ is a constant, $\mathrm{C}$ the current, and $d$ the distance between the electrodes.

The following table gives the values of $\left(V_{1}+V_{2}\right)$ got by subtracting $A C d$ from $V$, using the results given above. The value of $A$ was got from the measurements of the electric intensity between the electrodes by means of the equation $\mathrm{AC} d=\mathrm{X} d$.

We have $\frac{\mathrm{X}}{\mathrm{U}}=\mathrm{A}=0.03$, the current being expressed as before in terms of the corresponding galvamometer deflexion. Hence

$$
\mathrm{V}_{1}+\mathrm{V}_{2}=\mathrm{V}-0.03 \mathrm{C} d \text {. }
$$

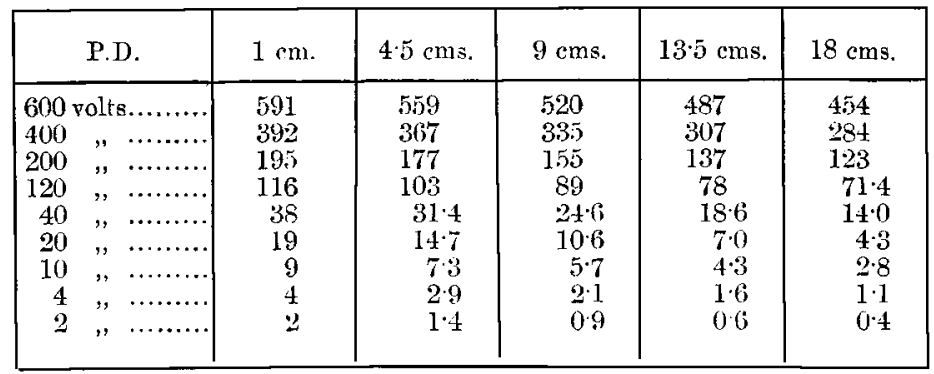


In fig. 3 these values of $\left(V_{1}+V_{2}\right)$ are plotted against the corresponding values of the current. The curve drawn is the parabola $\mathrm{C}=12 \cdot 8 \sqrt{\mathrm{V}_{1}+\mathrm{V}_{2}}$, and it will be seen that nearly all the points lie near this curve. It appears therefor $\theta$

Fig. 3.

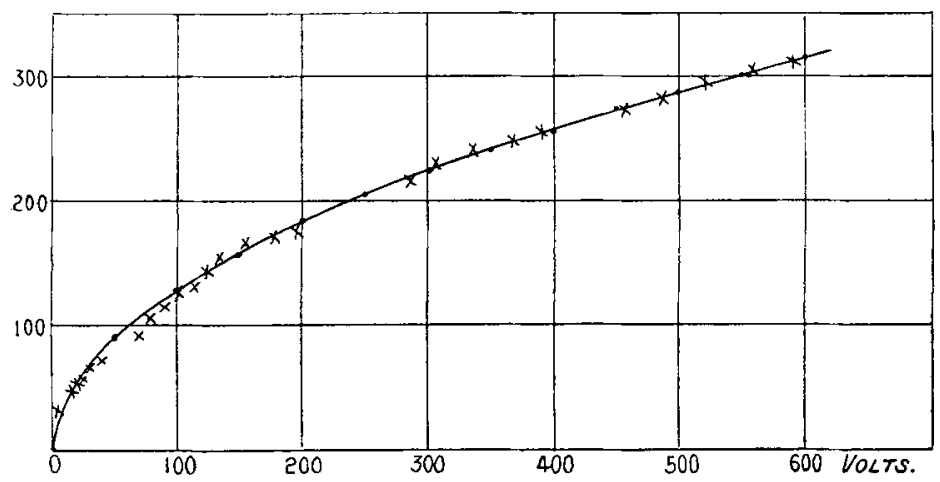

that the current varies approximately as the square root of $\left(\mathrm{V}_{1}+\mathrm{V}_{2}\right)$. Hence we have $\mathrm{C}=\mathrm{B} \sqrt{\overline{\mathrm{V}_{2}+\mathrm{V}_{1}}}$ nearly, where $\mathrm{B}=12 \cdot 8$ for the flame used, or $\mathrm{V}_{1}+\mathrm{V}_{2}=\frac{\mathrm{C}^{2}}{\mathrm{~B}^{2}}$.

But

so that

$$
\begin{gathered}
\mathrm{V}=\mathrm{V}_{2}+\mathrm{V}_{1}+\mathrm{AC} d, \\
\mathrm{~V}=\frac{\mathrm{C}^{2}}{\mathrm{~B}^{2}}+\mathrm{AC} d .
\end{gathered}
$$

Prof. J. J. Thomson * has given the theory of the variation of $\mathrm{V}$ with $\mathrm{C}$ in a uniformly ionized gas. He finds that when the current is fir from its maximum possible value so that there is a region between the electrodes where the electric intensity is uniform, then the relation between $\mathrm{V}$ and $\mathrm{C}$ is of the form $\mathrm{V}=a \mathrm{C}^{2}+b d \mathrm{C}$, where $a$ and $b$ are constants. The significance of $a$ and $b$ in Prof. Thomson's formula is morec over precisely that which has been deduced above for $\frac{1}{\bar{B}^{\text {q }}}$
and $\mathrm{A}$.

It appears therefore that the conductivity of the flame is due to approximately uniform ionization taking place throughout the region between the electrodes, and, further, that the current is always very far from its maximum possible value even when a P.D. of 600 volts is applied to electrodes only $1 \mathrm{~cm}$. apart in the Hame.

$$
\text { * 'Conduction of Flectricity throngh Gases,' p. } 73 .
$$


To further test the applicability of the formula

$$
\mathrm{V}=\frac{\mathrm{C}^{2}}{\mathrm{~B}^{2}}+\mathrm{AC} d
$$

to flames, the current between two vertical parallel platinum disk-electrodes placed symmetrically in an ordinary Bunsen flame was measured. One of these electrodes was $3 \mathrm{cms}$. in diameter, and the other consisted of a disk $1 \mathrm{~cm}$. in diameter surrounded by a guard-ring $3 \mathrm{cms}$. in diameter. The annular space between the disk and ring was $0.5 \mathrm{~mm}$. wide. The current between the large disk and the small one was measured, the guard-ring being kept at the same potential as the small disk. The results are shown in fig. 4 for a distance

Fig. 4.

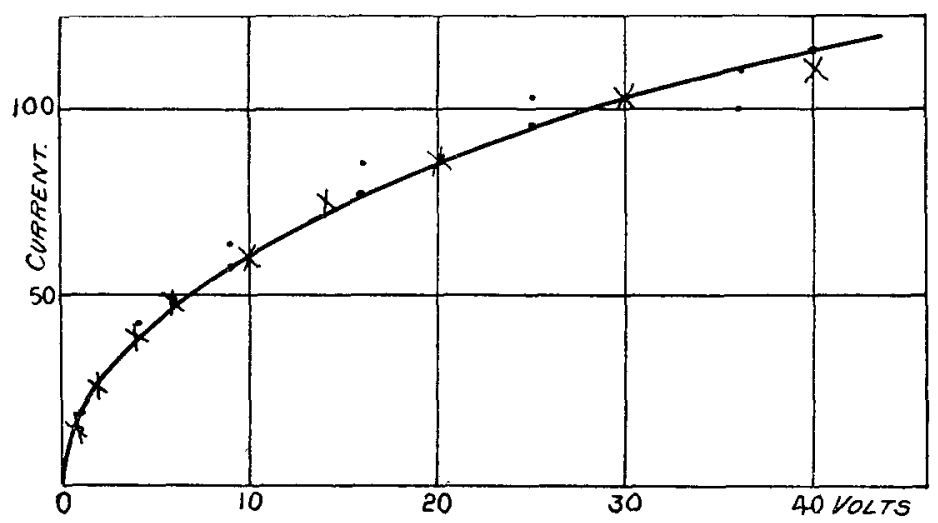

of $1 \mathrm{~cm}$. between the electrodes. The current was very nearly independent of the distance between the electrodes, which means that $\mathrm{AC} d$ in the formula $\mathrm{V}=\frac{\mathrm{C}^{2}}{\mathrm{~B}^{2}}+\mathrm{AC} d$ was negligible. (Consequently we should have $\mathrm{C}^{2}=\mathrm{B}^{2} \mathrm{~V}$. The curve drawn is the parabola $\mathrm{C}=19 \cdot 25 \sqrt{\mathrm{V}}$, and it will be seen that the points fall very near to it. The term $\mathrm{ACl}$ in this experiment was small, partly on account of the smallness of $d$ and partly because the flame was very hot, which of course diminishes $A$.

In previous experiments on the variation of $\mathrm{C}$ with $\mathrm{V}$ with the electrodes near together, no guard-ring was used, so that the relation obtained was probably complicated by the nonuniformity of the field at the edges of the electrodes.

1'hil. Mag. S. 6. Vol. 10. No. 58. Oct. 1905. 


\section{(2) The Effects due to introducing Salt Vapours into the Flame.}

The quartz-tube burner enables the effect of putting salt into different parts of the flame to be easily studied. A bead of an alkali salt on a platinum wire was put into different parts of the flame, the electrodes being about $18 \mathrm{cms}$. apart. It was found, in agreement with earlier results, that the current through the flame was not affected unless the salt vapour came in contact with the negative electrode, when a large increase in the current occurred. This result was previously explained by supposing that the salt vapour is only ionized when in contact with the hot electrodes, but it now appears that the true explanation is that the salt vapour is ionized anywhere in the flame, and that the absence of effect except close to the cathode is due to the non-uniformity of the potential gradient.

Two wires connected to a quadrant electrometer were supported in the flame so that the electric intensity between them could be measured. In one experiment, using a P.D. of 700 volts between the principal electrodes, the electric intensity was 1.6 volts per $\mathrm{cm}$. at about midway between the electrodes. On bringing a bead of $\mathrm{K}_{2} \mathrm{CO}_{3}$ into the flame just below the two wires, the P.D. between them fell to a very small fraction of a volt, but the current through the flame was not appreciably increased. The part of the flame occupied by the salt vapour is thus a much better conductor than the rest of the flame. In the experiment just described, the potential fall at the cathode was $700-18 \times 1 \cdot 6=671$ volts, and, as we have seen, $\mathrm{C}=\mathrm{A} \sqrt{\mathrm{V}_{2}}$. Now the effect of putting in the salt is to diminish the electric intensity to practically zero in the part of the flame occupied by the salt, which was a length of about 2 cms. of the thame. Thus putting in the salt must have increased the cathode fall by 3.2 volts, which according to the formula $\mathrm{C}=A \sqrt{V_{2}}$, since $V_{2}$ is $6 \pi 1$ volts, should have increased the current by one part in 400 . Now the deflexion due to the current in this experiment was about $200 \mathrm{mms}$. , so that putting in the salt ought to have increased the deflexion to $200.5 \mathrm{mms}$; but since the deflexion was never perfectly steady owing to small oscillations of the flame, so small an increase could not have been detected. It thus appears that the absence of effect on putting in salt, except close to the cathode, is not inconsistent with the view that the salt is ionized anywhere in the flame.

Fig. 5 shows the variation of the current with the distance between the electrodes for several P.D.'s when some $\mathrm{K}_{2} \mathrm{CO}_{3}$ 
was put on the cathode. The $\mathrm{K}_{2} \mathrm{CO}_{3}$ on the cathode fused and volatilized at a very constant rate, so that the current remained almost constant as long as any salt was left.

Fig. 5.

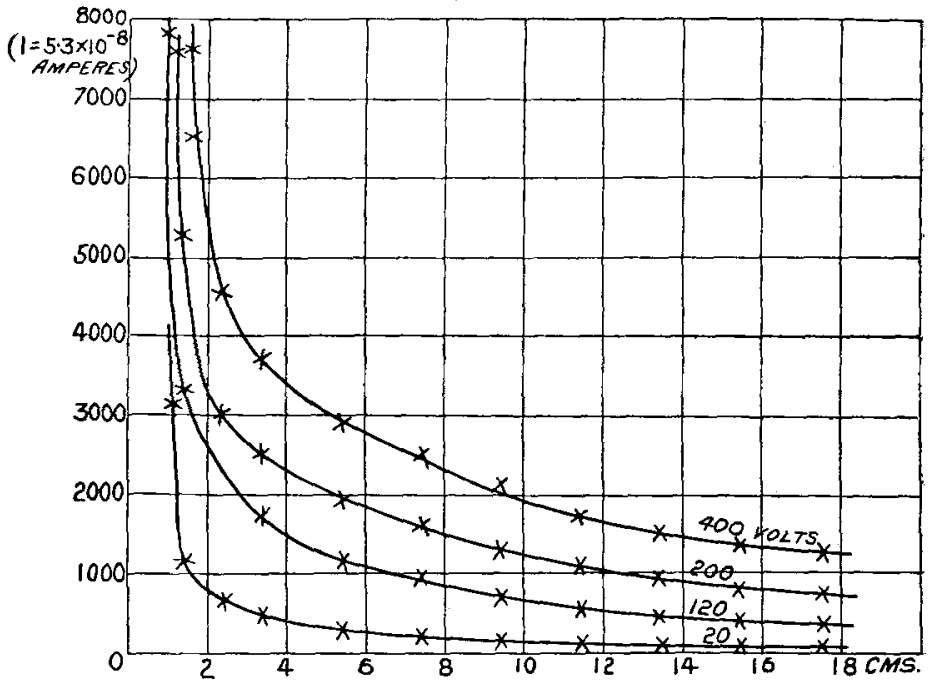

It will be seen that the current falls off rapidly as the distance between the electrodes is increased, this effect being much more marked than in the case of the flame alone.

Fig. 6.

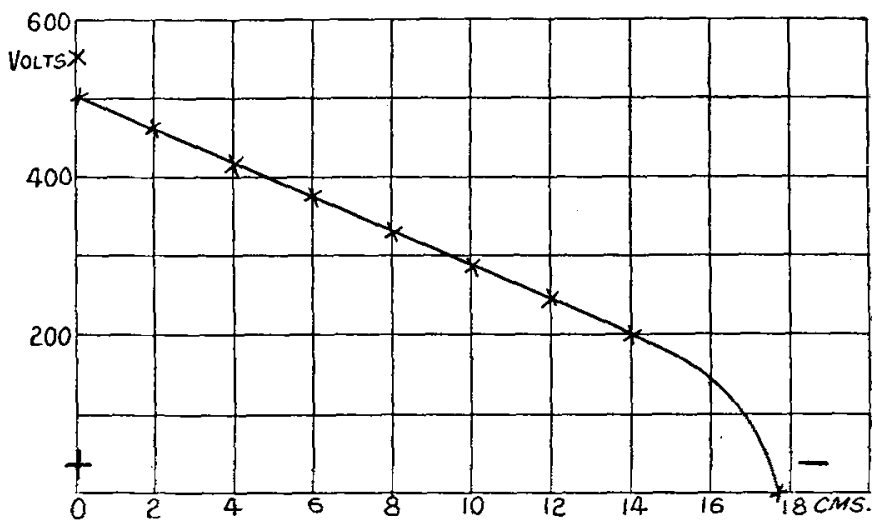

Fig. 6 shows the effect of putting salt on the cathode on the potential gradient. It will be seen, on comparing with fig. 2, that the cathode fall is greatly diminished, while the uniform gradient between the electrodes is increased. 
When the distance between the electrodes is large, the current with $\mathrm{K}_{2} \mathrm{CO}_{3}$ on the cathode is about 50 times greater than the current when no salt is present. The electric intensity in the region between the electrodes, however, is only three or four times greater, so that it seems as though putting salt on the negative electrode increased the conductivity of the rest of the flame. This effect is of a rather unexpected character, and the writer hopes shortly to carry out further experiments with the object of elucidating its real nature.

With salt on the cathode, most of the fall of potential occurs in the uniform gradient between the electrodes, so that the current which is proportional to the gradient varies roughly inversely as the distance between the electrodes and directly as the potential-difference.

It has been shown recently by F. L. Tufts* that coating the negative electrode with calcium oxide greatly diminishes the fall of potential at this electrode, and so inereases the current. This effect is clearly exactly of the same nature as the effect of putting an alkali salt on the electrode. Tufts also finds that when the negative electrode is coated with $\mathrm{CaO}$, then putting a bead of salt anywhere in the flame between the electrodes increases the current considerably. It was consequently to be expected that with salt on the negative electrode a similar effect wonld be obtained, and this was found to be the case. With the electrodes $18 \mathrm{cms}$. apart and $\mathrm{K}_{2} \mathrm{CO}_{3}$ on the cathode, putting a bead of $\mathrm{K}_{2} \mathrm{CO}_{3}$ inywhere in the flame increased the current about 10 per cent., and the same effect was obtained with beads of other alkali salts. Two beads put in at the same time in different positions increased the current about 20 per cent. The portion of the flame oceupied by the salt becomes a much better conductor than the rest of the flame, so that the electric iutensity in it hecomes very small. The electric intensity in the rest of the flame is consequently increased, and the current is proportional to this intensity. The salt from one head occupied ahout $2 \mathrm{cms}$. of the flame, so that with the electrodes $18 \mathrm{cms}$. apart an increase of $\frac{1}{8}$ in the current ought to have occurred, and with two beads $\frac{2}{7}$. Wirh the electrodes nearer together, the effect of putting in a bead was greater, as was to be expected. With the electrodes $9 \mathrm{cms}$ apart, putting in a bead increased the current about 20 per cent. It appears, therefore, that the salt vapour is ionized anywhere in the flame, and not only when in contact with the electrodes.

In an earlier paper (Phil. Trans. A, vol. excii. 1899) the

* F. L. Tufts, Phys. Zeitschr. v. p. 76 (i904), See also F. L. Tufts, \& J. Stalk, Phys. Zeitschr. v. p. 248 (1904). 
writer suggested that the salt vapour was only ionized when in contact with the hot platinum electrodes. This view enabled a great many experimental results to be simply explained, but it appears now that the true explanation of these results is the smallness of the potential gradient in the fiame, except close to the electrodes. It was supposed previously that when the P.D. used was large, so that the current only increased slowly with increasing P.D., that then the current was nearly at its maximum possible value, and so was a measure of the number of jons formed between the electrodes. It is clear now that this supposition was incorrect, and that the current is really always very far from its saturation value. It is of course probable that some surface ionization on the hot electrodes does occur, but, at any rate, when the electrodes are not very near together, it does not appear to be sufficient to appreciably influence the conductivity of the flame.

The view that the salt vapour is ionized throughout the flame was adopted by Arrhenius (Wied. Ann. xlii. p. 18, 1891), E. Marx (Ann. de Phys. ii. pp. 768, 798, 1900), and by F. L. Tufts and Stark in the papers referred to above.

In conclusion, I wish to say that my best thanks are due to Prof. J. J. Thomson for valuable advice and kind interest shown during the carrying out of these experiments.

LVI. Contact with Dielectrics. By Rollo Appleyard *.

OBJECTS.

To examine :-

(1) Whether tinfoil electrodes, pressed against a sheet of dielectric by indiarubber disks, enable accurate determinations of dielectricresistance to be made.

(2) The effect upon dielectric-resistance of change of load on such tinfoil electrodes, in the case of press-spahn.

(3) The effect upon dielectric-resistance of increase or decrease of voltage in the case of press-spahn between tinfoil electrodes.

(4) The rate and direction of the change of deflexion in direct-deflexion tests on press-spahn, and to determine in how far these changes result. from surfact conditions, and in how far from internal stresses.

(5) The effect of reversals of voltage upon dielectric-resistance.

(6) The effect of prolonged " electrification."

(7) To indicate the probable limits of accuracy with mercury electrodes.

(8) To point out that Price's guard-wire can be used in sheet tests to eliminate leakage over the sheet surface, as well as over the instruments.

(9) The retentive force between electrodes and dielectrics.

* Communicated by the Physical Society: read June 16, 1905. 